\title{
Enseñar y aprender sobre naturaleza de la ciencia mediante el análisis de controversias de historia. Resultados y conclusiones de un proyecto de investigación didáctica
}

\author{
Teach and learn about the nature of science through the analysis of history \\ controversies. Results and conclusions of a didactic research project
}

\section{Ensinar e aprender sobre a natureza da ciência através da análise de controvérsias históricas. Resultados e conclusões de um projeto de pesquisa didática}

\author{
Adriana Patricia Gallego Torres ${ }^{1}$
}

\section{Resumen}

Se presenta una reseña del libro escrito por los investigadores José Antonio Acevedo-Díaz, Antonio García-Carmona y María del Mar Aragón-Méndez, titulado Enseñar y aprender sobre naturaleza de la ciencia mediante el análisis de controversias de historia.

Palabras clave: naturaleza de la ciencia, historia de la ciencia, controversias científicas.

\section{Abstract \\ This article presents a review of the book writ- ten by the researchers José Antonio Acevedo- Díaz, Antonio García-Carmona and María del Mar Aragón-Méndez, entitled Enseñar y aprender sobre}

naturaleza de la ciencia mediante el análisis de controversias de historia.

Keywords: nature of science, history of science, scientific controversies.

\section{Resumo}

Este artigo apresenta uma revisão do livro escrito pelos pesquisadores José Antonio Acevedo-Díaz, Antonio Garcia-Carmona e María del Mar Aragón-Méndez, intitulado Enseñar y aprender sobre naturaleza de la ciencia mediante el análisis de controversias de historia.

Palavras-chaves: natureza da ciência, história da ciência, controvérsias científicas. 


\section{Reseña del libro}

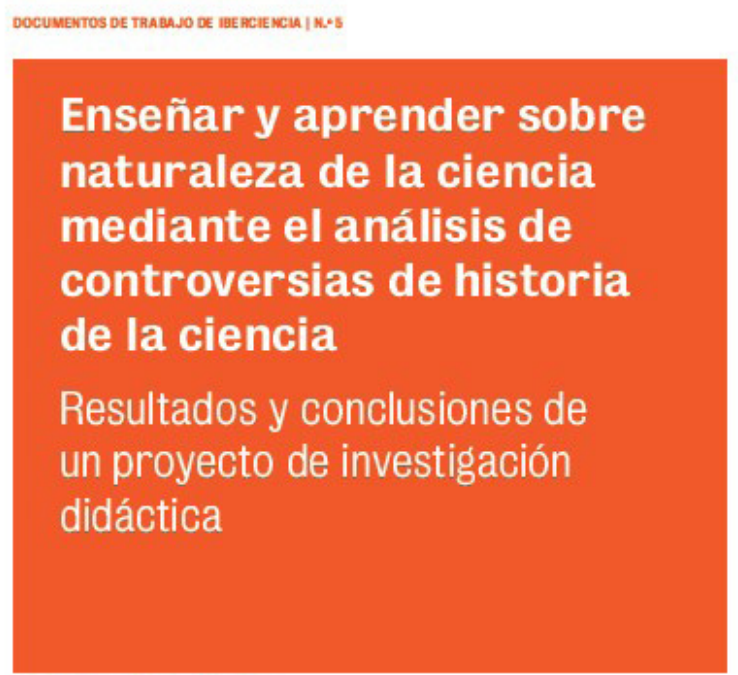

José Antonio Acevedo-Dlaz

Antonio Garcla-Carmona

María del Mar Aragon-Méndez

\section{ibsrciencia}

El propósito de este libro es fomentar un debate crítico y constructivo sobre cómo reconceptualizar la naturaleza de la ciencia (NDC) en la educación científica. Para ello, se plantea la implementación de textos de controversias de la historia de la ciencia (HDC), encaminadas a integrar de manera explícita y reflexiva la NDC en el currículo de ciencias, de forma que contribuya a la comprensión de aspectos epistémicos y no-epistémicos de esta.

\section{Fundamentos conceptuales}

\section{Naturaleza de la ciencia}

En este apartado los autores hacen un análisis riguroso sobre las diferentes posturas que se han
José Antonio Acevedo-Díaz /

Antonio García-Carmona /

María del Mar Aragón-Méndez

Edición realizada con el apoyo de la Consejería de Economía y Conocimiento de la Junta de Andalucía, Madrid: OEI. ISBN: 9788476662229 trabajado alrededor de la NDC en los últimos años. La llegan a definir como:

[...] un meta-conocimiento sobre la ciencia, que proviene de las reflexiones interdisciplinares planteadas desde la filosofía, la historia y la sociología de la ciencia, y por parte de algunos científicos y educadores de ciencia. Puesto que la ciencia es poliédrica y dinámica, no es fácil definir con precisión el concepto de NDC; aunque, de manera muy general, puede decirse que trata de todo aquello que caracteriza a la ciencia como una forma particular de construcción de conocimiento sobre el mundo físico o natural. (Acevedo y García-Carmona, 2016)

Los autores plantean la necesidad de comprender la relación existente entre la NDC y la cultura 
científica, que incluye diferentes saberes y nociones sobre la ciencia, sus métodos, desarrollos y las influencias mutuas entre ciencia, tecnología y sociedad (CTS).

De igual manera, en el libro se afirma de forma muy acertada que:

Una buena comprensión de la NDC es condición necesaria, pero insuficiente para que el profesorado de ciencia incorpore a sus clases contenidos de NDC; hace falta mucho más. Es frecuente que profesores que han logrado adquirir una comprensión bien informada y actualizada de algunos aspectos básicos de la NDC no intentan luego enseñarlos de manera explícita y reflexiva, o adoptan enfoques poco fructíferos para ello.

\section{Historia de la ciencia}

Desde hace varias décadas, diversos investigadores han recalcado la importancia de incluir la HDC en el currículo de ciencia escolar como herramienta para contribuir a la comprensión de la NDC. Una de las formas de trabajar la HDC en el aula de clase es mediante controversias científicas, debido a que no solamente intervienen los aspectos epistémicos científicos, sino que también propicia la oportunidad de considerar también los aspectos no-epistémicos de la NDC. La propuesta que desarrolla el libro acude al uso de las controversias científicas desde un análisis crítico-reflexivo de los aspectos reconocibles en las narraciones de las controversias de HDC propuestas para tal fin.

\section{Aspectos metodológicos de la propuesta}

Dando respuesta al propósito general de la investigación, se escogieron cuatro controversias científicas. En estas se plantean diversas cuestiones sobre aspectos epistémicos y no-epistémicos de NDC reconocibles en las narraciones, que los autores definen de forma clara y precisa. En concreto, las controversias son las siguientes: a. Semmelweis y la fiebre puerperal.

b. La controversia entre Pasteur y Liebig sobre la fermentación.

c. Rosalind Franklin y la doble hélice del ADN.

d. La controversia entre Pasteur y Pouchet sobre la generación espontánea.

La propuesta metodológica planteada formula aspectos relacionados con la investigación cualitativa y destaca la confirmabilidad y la credibilidad que aportan este tipo de estudios. Los diseños experimentales planteados incluyen una ruta de trabajo y una rúbrica de evaluación para cada uno los siete estudios realizados: cuatro en la formación inicial del profesorado de ciencias de educación secundaria y tres en la educación científica de estudiantes de educación secundaria (Sistema Educativa de España-ESO y bachillerato; edades entre 16 y 18 años).

Una vez analizadas cada una de las implementaciones en el aula, los autores establecen las conclusiones y exponen las principales implicaciones educativas del proyecto llevado a cabo.

\section{A manera de conclusión}

Los autores presentan un desarrollo teórico sobre la NDC. Este parte de una exhaustiva revisión crítica de las propuestas planteadas en las últimas décadas, que reflejan falencias estructurales al basarse principalmente en la construcción de los conocimientos. Lo anterior, desde una base epistemológica, y se propone un enfoque innovador que incluye no solo los aspectos epistemológicos propios de la ciencia y sus métodos, sino también los no-epistemológicos.

La propuesta educativa que desarrollaron se basa en el uso de controversias de HDC para enseñar y aprender sobre NDC desde un enfoque explícito y reflexivo, tanto en la educación secundaria como en la formación inicial del profesorado de ciencias de educación secundaria.

Los resultados obtenidos en el estudio les permitieron afirmar que la propuesta contribuye al 
desarrollo de una alfabetización científica más completa; porque muestran que la NDC es un meta-conocimiento clave de la cultura científica. Esta se construye a partir de las aportaciones de la historia, la filosofía y la sociología de la ciencia.

El libro representa un gran aporte teórico y metodológico al campo de conocimiento denominado NDC. Sus reflexiones y contribuciones constituyen un modelo para trabajar la historia de la ciencia en el aula de educación secundaria y en la formación de docentes.
El libro se encuentra disponible en www.oei.es/ historico/divulgacioncientifica/?Ensenar-y-aprender-sobre-naturaleza-de-la-ciencia-mediante-el-analisis-de

\section{Referencia}

Acevedo, J. A. y García-Carmona, A. (2016). "Algo antiguo, algo nuevo, algo prestado». Tendencias sobre la naturaleza de la ciencia en la educación científica. Revista Eureka sobre Enseñanza y Divulgación de las Ciencias, 13(1), 3-19. 